\title{
Development of histological detection methods of cottage cheese falsification
}

\author{
Liudmila Reznichenko ${ }^{1, *}$, Elena Nikolenko², Sergei Noskov $^{2}$ and Roman Shcherbinin ${ }^{1}$ \\ ${ }^{1}$ Belgorod State Agricultural University named after V. Ya. Gorin, Mayskiy settlement, 308503, Belgorod region, Russia \\ ${ }^{2}$ Belgorod IVL, 32, Studencheskaya St., Belgorod, 308023, Russia
}

\begin{abstract}
Information falsification of fermented milk products is a consumer fraud using inaccurate or distorted product information. The purpose of falsification is to obtain illegal profits by reducing the production cost as a result of the unauthorized replacement of qualitative biological value of raw materials with less valuable. Most modern methods of falsification, one way or another, are restricted to changes in technology, the use of cheap raw materials and the subsequent bringing of physicochemical indicators to the established requirements of regulatory documents. The production and realization of counterfeit products also contributes to unfair competition in the food market, as a result of which manufacturers of quality goods are at a disadvantage. The purpose of this paper is to develop methods for determining the cottage cheese falsification, in particular, the defining dairy raw materials the product is made of (natural milk or skimmed milk powder). The research result is that the histological method has been developed for the first time. The method is capable of determining the type of milk raw material in the cottage cheese production with high accuracy, and preventing information falsification of this product.
\end{abstract}

\section{Introduction}

The range and production of dairy products in Russia has significantly increased in recent years. Hundreds of their items, many of which are actively advertised, are located on the market of fermented milk products being in high demand by the population. Therefore, the temptation to falsify or increase production volumes by means of various types of falsifications is always present both for the seller and the producer of [1]. Thus, problems with conducting a comprehensive examination of the authenticity of fermented milk products of all types arise when they enter the Russian markets.

The problem of dairy products identification has gained a particular relevance in connection with updating the dairy products range due to the implementation of components from vegetable raw materials (vegetable oils, soy proteins, etc.), and an increase in the number of types and varieties of dairy products [2].

The ability to correctly identify the product can lead to the exclusion of falsified products realization, therefore, it is very important to consider methods of its authentication $[3,4]$.

The final result of identification is the confirmation of goods to the requirements by regulative documents, technical specifications or contracts. The result is the authenticity or discrepancy of the product (negative result stated as a product falsification). Both positive and negative results are crucial for determining the future fate of the goods.
The development of new and the adjustment of existing research methods are necessary to improve identification methods. Since the group of organoleptic methods as a whole depends on the human factor and measuring methods are based on the use of technical means [5].

Cottage cheese is often falsified as it is an entirely useful product. The proteins contained in it are almost completely absorbed by the human body, much better than the proteins of meat, fish, and even milk. Amino acids normalize the liver, lower cholesterol, and strengthen the nervous system. Calcium reinforces bone tissue, improves oxygen supply to tissues, and helps treat allergies. Moreover, cottage cheese is rich in phosphorus, iron, magnesium, beta-carotene, vitamins A, B1, B2, C, D, E, and others. The milk fat contained in the cottage cheese comprises all known fatty acids (including especially valuable arachidonic and linoleic). This product is a stockpot of nutrients. Besides, many people do not absorb dairy products due to lactose, which is absent in the cottage cheese $[6,7]$.

Milk fats when falsifying cottage cheese are replaced with cheap oils such as palm and coconut. They harm the body without heat treatment, as they settle on the stomach walls and adversely affect blood vessels.

Cottage cheese is produced from pasteurized milk by curdling with rennet and/or lactic acid, followed by separation of the whey and without molding. Protein pastes or curd products with various excipients can be obtained from cottage cheese. The addition of consistency stabilizers is not allowed in cottage cheese.

Corresponding author: reznichenko6531@gmail.com, bmvl-chem@yandex.ru 
It is a cheese mass in which cottage cheese grains are clearly distinguished and covered with cream.

Identification indicators of this product are established by regulatory or technical documents or standards of organizations.

Falsification is a process in which the quality or naturalness of a given substance is impaired by the addition of a foreign substance that is worse in quality or by the removal of important (basic) elements (or components).

Counterfeit foods have the reduced nutritional and biological value and do not meet the body's need for basic substances and energy. According to the Federal Law No. 29 of 2 January 2000 On Quality and Food Safety, such products are considered substandard and dangerous, withdrawn from circulation and must be disposed or destroyed [8].

Considering the urgency of the arisen problems, it is necessary to implement programs to ensure the quality and safety of goods being in circulation on the Russian market. Therefore, a need to identify unscrupulous manufacturers and take regulatory measures against them, as well as suppress attempts to produce lowquality goods and deceive consumers has emerged.

The most valuable is cottage cheese made from natural milk. However, some manufacturers replace it with skimmed milk powder, which is information fraud [9].

ELISA (enzyme-linked immunosorbent assay) is used to detect the content of skimmed milk powder in fermented milk products. The disadvantages of this method are the high labour intensity, low accuracy, duration, and high cost.

However, we have developed a new histological method for determining the falsification of cottage cheese. In particular, this method will allow determining the presence of milk powder in the product with high accuracy, as well as to find out whether natural milk or milk powder was used in the production of cottage cheese.

The purpose and objectives of the research. The purpose of this paper is to develop a histological method for determining the milk raw material from which the cottage cheese is made of: natural milk or skimmed milk powder.

In accordance with the purpose, the following tasks have been solved:

- prepare histological sections of cottage cheese made from natural milk and milk powder;

- compare and analyze histological sections of both products.

\section{Material and method of analysis}

Two cottage cheese samples (control and experimental) were used as the studied materials. The control sample of cottage cheese was made from natural milk, the experimental - from milk powder.

The following equipment was used for the experiments: microtome cryostat HM 525 and binocular microscope "Axiostar plus" (with photofixation).

We have made cottage cheese histosections of the control and experimental samples. Sections were stained with Sudan III (cerasine red).

\section{Test results and discussion}

Two samples of $0.5 \%$ fat cottage cheese $100 \mathrm{~g}$ each were taken for the experiment $(1-$ control and $2-$ experimental). The control sample is cottage cheese made from natural milk, the experimental one is cottage cheese made from skimmed milk powder.

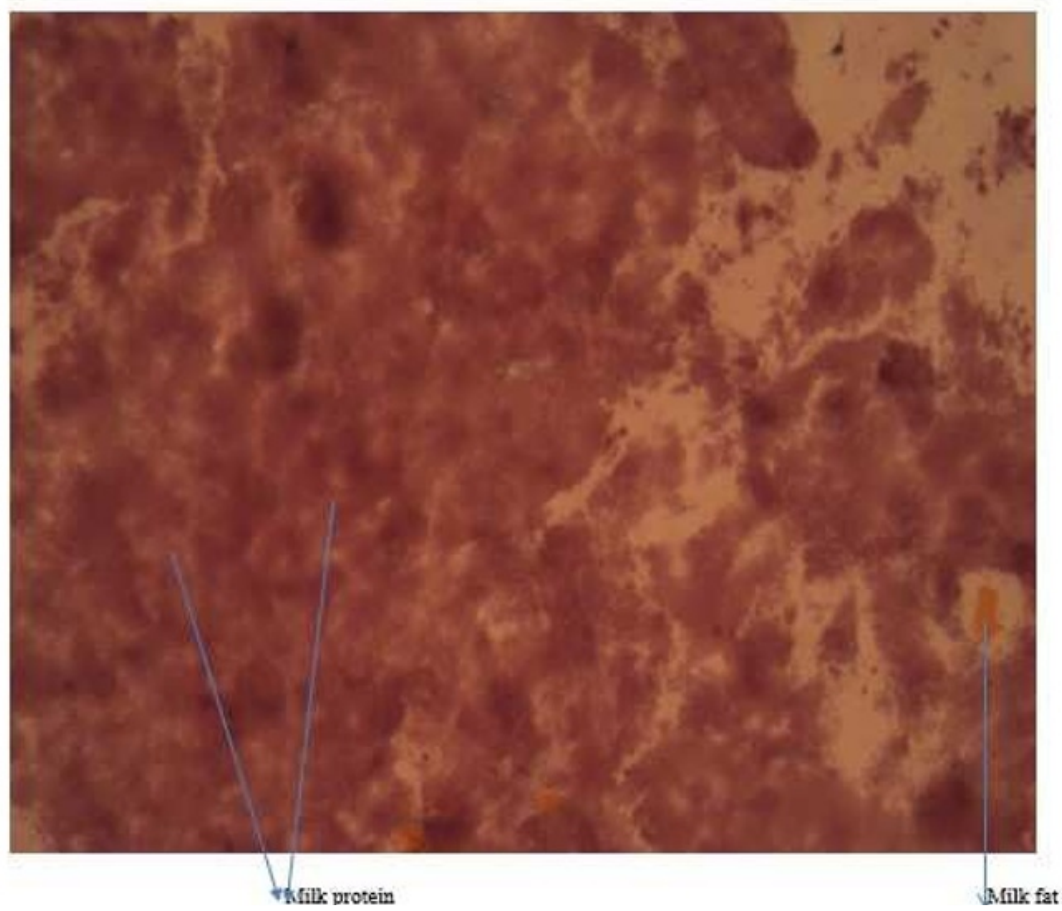

Fig. 1. Histological section of cottage cheese made from natural milk (control sample). Stained with Sudan III. Magnification $\times 100$. 


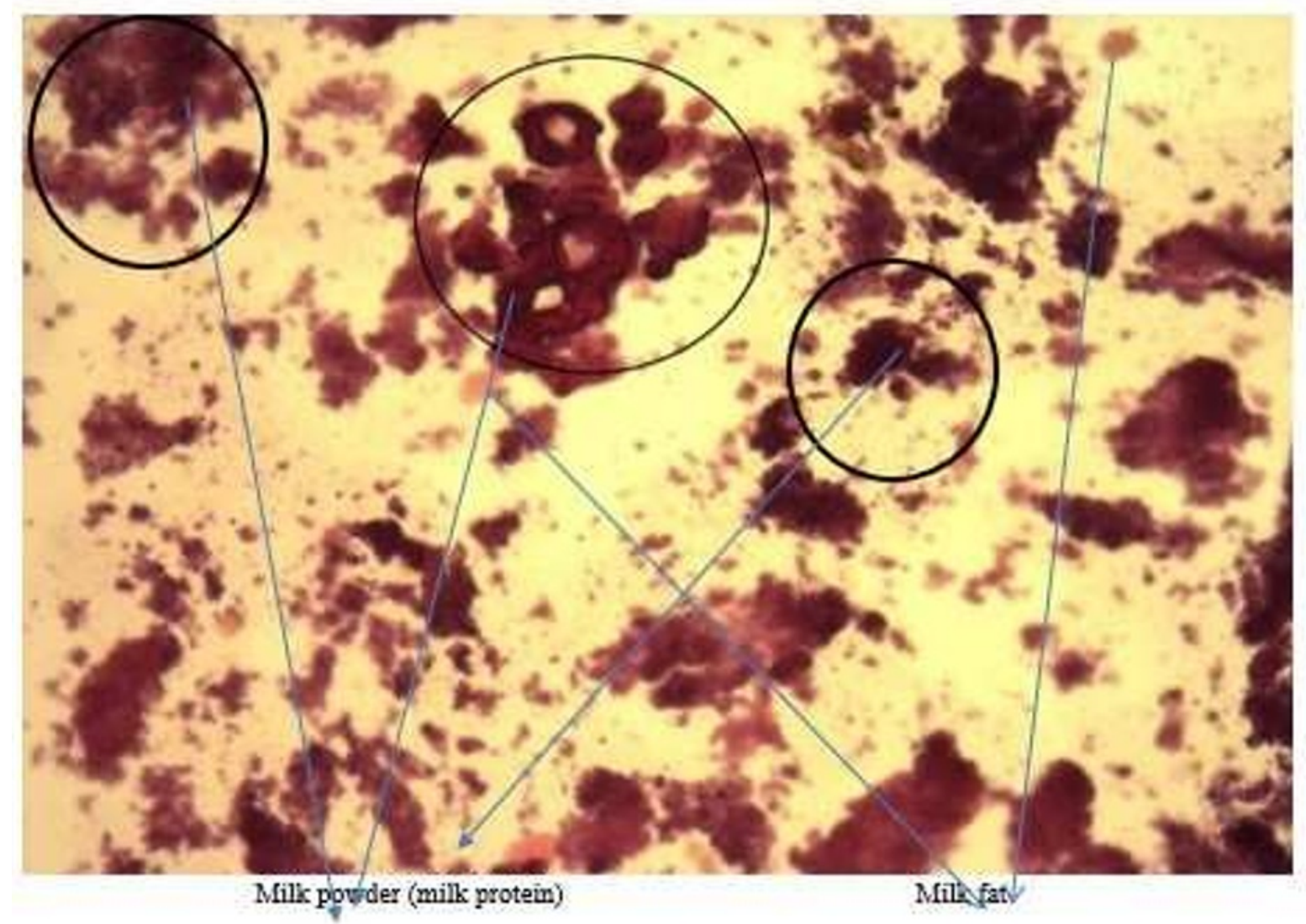

Fig. 2. Histological section of cottage cheese made from milk powder (control sample). Stained with Sudan III. Magnification $\times 100$.

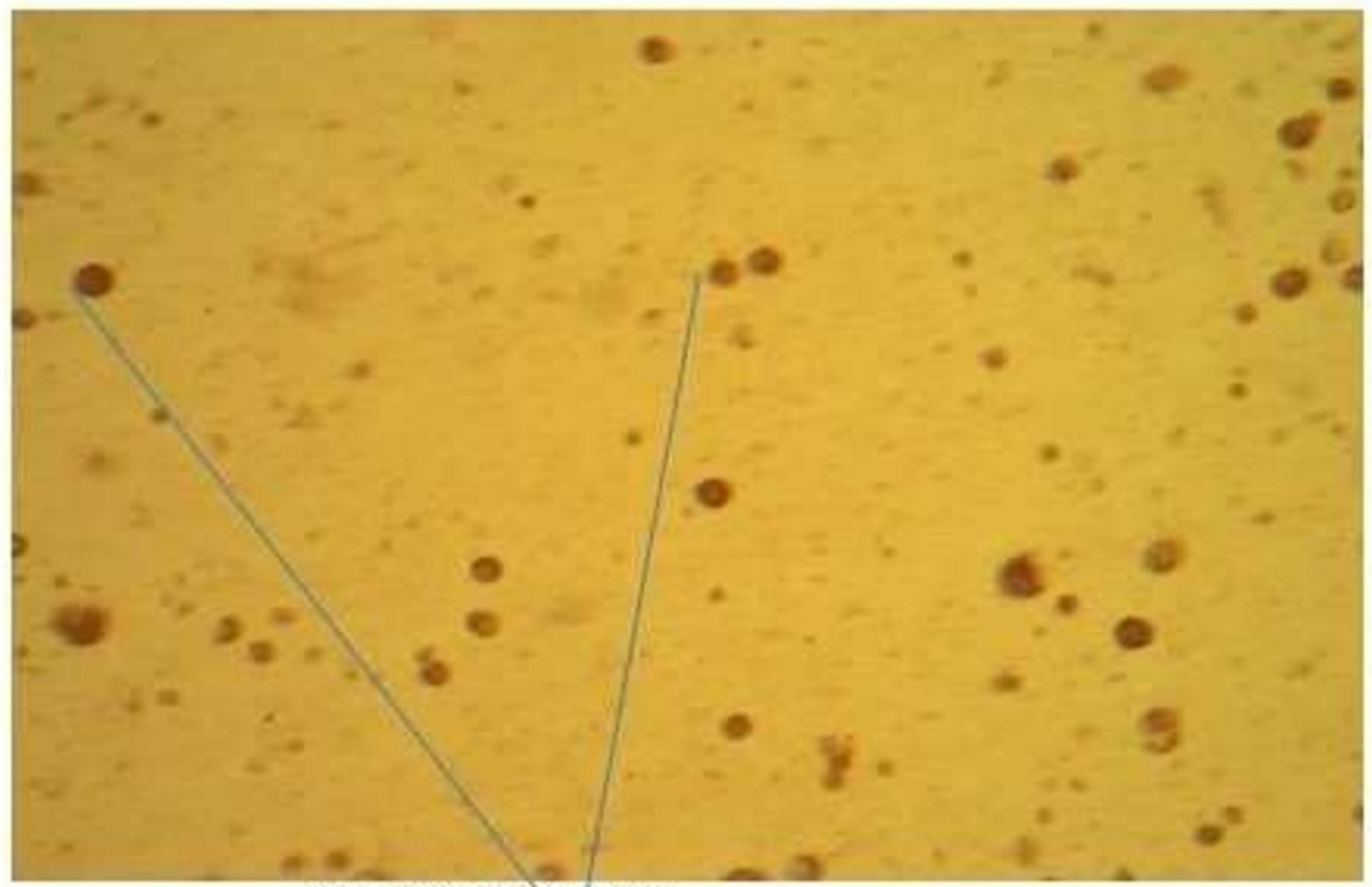

Milk protein of milk powder

Fig. 3. Histological section of milk powder. Stained with Lugol. Magnification $\times 100$. 
The results of the conducted studies are presented in Figures 1 and 2.

It is seen from the data shown in Figure 1 that milk protein is represented by clusters of light-violet color of an oval shape which are evenly distributed throughout the section in the cottage cheese made from natural milk. Milk fat is submitted in the form of a yellow spot of irregular shape.

Figure 2 demonstrates milk protein from milk powder in the form of shapeless lumps of dark purple color. Milk fat is similar to oval spots of orange color.

Figure 3 shows a histological section of skimmed milk powder where milk protein is represented by brown rounded formations.

\section{Conclusion}

Fermented milk products are essential to the human nutrition. This fully applies to cottage cheese and its products characterized by a high content of protein, milk fat, calcium salts, and phosphorus. The production of cottage cheese is a labor-intensive process that requires a significant amount of milk. Dairy manufacturers often lack raw materials, especially in winter, herewith, milk quality is often low.

According to GOST 31453-2013, cottage cheese is a fermented milk product made with the use of starter microorganisms. Lactococci or a mixture of lactococci and thermophilic lactic streptococci and acid or acidrennet coagulation of proteins, followed by removal of whey by self-pressing and (or) pressing are among them. The product, depending on the milk raw material, is made from whole milk, normalized milk, skimmed milk, reconstituted milk and their mixtures [10, 11]. The raw materials used for this product manufacture must meet the safety requirements [12-14].

The most valuable is cottage cheese received from natural milk. However, with information fraud, the product from skimmed milk powder is often presented as made from natural cow's milk.

Herewith, milk powder components are used in the production of cottage cheese. The technological technique allows providing the population with complete, although falsified in relation to information, food products with the absence of natural milk. The method also permits reducing the shortage of milk raw materials that occurs at large dairy enterprises during the off-season or at factories located at a considerable distance from dairy farms.

Whole milk and skimmed milk powder, as well as individual components of milk, such as milk protein concentrates, whey protein concentrates and their isolates can be used as raw materials. Moreover, individual fractions of proteins are able to increase the biological value and functional properties of the products. Furthermore, these components have a considerable impact on the formation of the product structure.

Thus, according to the studies, the developed histological method determines the used raw materials in the production of cottage cheese with high accuracy which makes it possible to identify unscrupulous manufacturers of fermented milk products.

\section{References}

1. L.D. Serazhutdinova, M.A. Malykh et al., Identification of dairy products: problems and solutions, Conform. Assessm. Methods, 1, 22-25 (2013)

2. D.N. Kovalenko, Falsification of milk and dairy products, Milk proc., 3, 8-11 (2011)

3. L.V. Reznichenko, E.N. Nikolenko, S.B. Noskov, Development of histological methods for detecting sour cream falsification, Veter. Sci., 10, 54-57 (2019)

4. V.D. Kosoi, M.Iu. Merkulov, S.B. Iudina, Quality control of dairy products by methods of physicochemical mechanics (GIORD, St. Petersburg, 2005) 280 p.

5. M.V. Zabolotnykh, Quality and safety of raw materials and food products in modern conditions, Bull. of Omsk State Agrar. Univer. named after P.A. Stolypin, 3(15), 29-32 (2014)

6. S.A. Bredikhin, Technology and technique of milk processing (Kolos, Moscow, 2003) 400 p.

7. N.N. Lipatov, K.I. Tarasov, Reconstituted milk (theory and practice of the production of reconstituted dairy products) (Agropromizdat, Moscow, 1985) $256 \mathrm{p}$.

8. On Quality and Food Safety, the products are considered substandard and dangerous, withdrawn from circulation and must be disposed or destroyed. Federal Law of 2 January 2000, no. 29.

9. V.V. Kuznetsov, G.G. Shiller, The use of milk powder components in the food industry, Handbook (GIORD, St. Petersburg, 2006) 480 p.

10. GOST 31534, Grained cottage cheese. Technical specifications

11. GOST 31453-2013, Cottage cheese. Technical specifications

12. GOST R 58340-2019, Milk and dairy products. Method of sampling from a sales shelf and delivering samples to a laboratory

13. Technical regulation of the Customs Union TR CU 021/2011 On food safety

14. Technical regulation of the customs union TR CU $033 / 2013$ on the safety of milk and dairy products

\footnotetext{
* Corresponding author: reznichenko6531@gmail.com, bmvl-chem@yandex.ru
} 